\title{
ON THE EXTREME POINTS OF SOME CLASSES OF HOLOMORPHIC FUNCTIONS
}

\author{
NICOLAS SAMARIS \\ Department of Mathematics \\ University of Patras \\ Patras 26110 Greece \\ (Received February 1, 1994 and in revised form June 30, 1994) \\ ABSTRACT. Let $U$ be the unit disk, $D \supset U$ an open connected set and $z_{0} \in D$. Let also \\ $\mathbf{P}\left(z_{0}, c, D\right)$ be the class of holomorphic functions in $D$ for which $f\left(z_{0}\right)=c$ and $\operatorname{Ref}(z)>0$ in $U$.
} We find the extreme points of the class $\mathbf{P}\left(z_{0}, c, D\right)$.

KEY WORDS AN PHRASES. Extreme points, positive real part.

1991 AMS SUBJECT CLASSIFICATION CODES 30C45.

\section{INTRODUCTION.}

Let $U$ be the unit disk $\{z:|z|<1\}, D \supset U$ an open connected set, $z_{0} \in D$ and $\mathbf{H}(D)$ be the class of holomorphic functions in $D$. By $\mathbf{P}\left(z_{0}, c, D\right)$ we denote the class of the functions $f \in \mathbf{H}(D)$ for which $f\left(z_{0}\right)=c$ and $\operatorname{Re} f(z)>0$ in $U$. Let $\mathbf{E P}\left(z_{0}, c, D\right)$ be the subclass of the extreme points of the above class for $\mathbf{P}=\mathbf{P}(0,1, U)$ it has proven [1] that

$$
\mathbf{E P}=\left\{(\epsilon+z)(\epsilon-z)^{-1}: \epsilon \in \partial U-D\right\},
$$

In this paper we find the points of the subclass $\operatorname{EP}\left(z_{0}, c, D\right)$.

2. MAIN RESULT.

THEOREM. (i) If $\left(1-\left|z_{0}\right|\right) \operatorname{Rec} \leq 0$ then $\operatorname{EP}\left(z_{0}, c, D\right)=0$. (ii) If $\left(1-\left|z_{0}\right|\right) \operatorname{Rec}>0$ then $f \in \mathbf{E P}\left(z_{0}, c, D\right)$ iff it has the form

$$
f(z)=x_{1}\left(\frac{\epsilon+z}{\epsilon-z}\right)+i x_{2},
$$

where $\epsilon \in \partial U-D, x_{1}=\operatorname{Rec}\left[\operatorname{Re}\left(\frac{\epsilon+z_{0}}{\epsilon-z_{0}}\right)\right]^{-1}$ and $x_{2}=\operatorname{Imc}-x_{1} \cdot \operatorname{Im}\left(\frac{\epsilon+z_{0}}{\epsilon-z_{0}}\right)$

PROOF. Let $f \in \mathbf{P}\left(z_{0}, c, D\right)$ with $f(z)=\sum_{n=0}^{\infty} \alpha_{n} z^{n}$ in $U$. Let also $r<1, S$ be a complex number and $M>0$ such that $0<2|S|<M$ and $z \in \partial U$. Since

$$
\left[1 \pm \frac{1}{M}\left(S z+\bar{S} z^{-1}\right)\right] \operatorname{Ref}(r z)>0
$$

then

$$
R e\left[f(r z) \pm \frac{1}{M}\left(S z f(r z)+\bar{S} \sum_{n=0}^{\infty} \alpha_{n} r^{n} z^{n-1}+S \bar{\alpha}_{0} z\right)\right]
$$

By the maximum principle for harmonic functions it follows that (1) holds for every $z \in U$. Therefore for $r \rightarrow 1$ we have $\operatorname{Re}\left(f(z) \pm u_{1}(z)\right)>0$ in $U$ where

$$
u_{1}(z)=\frac{1}{M}\left[S z^{-1}\left(f(z)-\alpha_{0}\right)+S \bar{\alpha}_{0} z+S z f(z)\right]
$$


Choosing appropriate $S \neq 0$ we get $\operatorname{Re} u_{1}\left(z_{0}\right)=0$. Setting $u(z)=u_{1}(z)-i \operatorname{Im} u_{1}\left(z_{0}\right)$ from $u\left(z_{0}\right)=0$ it follows that $f \pm u \in \mathbf{P}\left(z_{0}, c, D\right)$.

Let now $f \in \mathbf{E P}\left(z_{0}, c, D\right)$. Then it is obvious that $u(z)=0$ in $D$. If we set $S=|S| e^{i^{\left(x+\frac{\pi}{2}\right)}}$ then from equality $u=0$ we conclude that $f$ has the form

$$
\begin{gathered}
f(z)=\frac{\xi_{1}\left(1+z^{2} e^{2 i \varphi}\right)+\xi_{2} z e^{i \varphi}}{\left(1-z^{2} e^{2 i \varphi}\right)}+i \xi_{3}= \\
\frac{1}{2}\left(\xi_{1}+\frac{\xi_{2}}{2}\right)\left(\frac{1+e^{i \varphi} z}{1-e^{i \varphi} z}\right)+\frac{1}{2}\left(\xi_{1}-\frac{\xi_{2}}{2}\right)\left(\frac{1-e^{i \varphi} z}{1+e^{i \varphi} z}\right)+i \xi_{3}
\end{gathered}
$$

where $\xi_{1}, \xi_{2}, \xi_{3} \in \mathbb{R}$.

We now prove that $\left|\xi_{2}\right|=2 \xi_{1}$. From the Caratheodory's inequality we have $\left|f^{\prime}(0)\right| \leq 2 \operatorname{Re} f(0)$ and hence $\left|\xi_{2}\right| \leq 2 \xi_{1}$. If $\left|\xi_{2}\right|<2 \xi_{1}$ then there are $\xi_{1}^{*}, \xi_{2}^{*}$ such that $0<\left|\xi_{1}^{*}\right|<\xi_{1}+\frac{\xi_{2}}{2}, 0<\left|\xi_{2}^{*}\right|<$ $\xi_{1}-\frac{\xi_{2}}{2}$, and $R e u_{1}^{*}\left(z_{0}\right)=0$, where

$$
u_{1}^{*}(z)=\xi_{1}^{*}\left(\frac{1+e^{2 \varphi} z}{1-e^{i \varphi} z}\right)+\xi_{2}^{*}\left(\frac{1-e^{i \varphi} z}{1+e^{2 \varphi} z}\right)
$$

Setting $u^{*}(z)=u_{1}^{*}(z)-i \operatorname{Im} u_{1}^{*}\left(z_{0}\right)$ then $f \pm u^{*} \in \mathbf{P}\left(z_{0}, c, D\right)$. Since $f \in \mathbf{E P}\left(z_{0}, c, D\right)$ it follows that $u^{*}=0$ and hence $\xi_{1}^{*}=\xi_{2}^{*}=0$. Therefore if $f \in \operatorname{EP}\left(z_{0}, c, D\right)$ then $\left|\xi_{2}\right|=2 \xi_{1}$ and hence $f$ has the form

$$
f(z)=x_{1}\left(\frac{\epsilon+z}{\epsilon-z}\right)+i x_{2}, x_{1}>0, x_{2} \in \mathbb{R}, \epsilon \in \partial U-D .
$$

From (4) we have

$$
x_{1}=\operatorname{Rec}\left[\operatorname{Re}\left(\frac{\epsilon+z_{0}}{\epsilon-z_{0}}\right)\right]^{-1}>0 \text { and hence }\left(1-\left|z_{0}\right|\right) \operatorname{Rec}>0 .
$$

Let $f \in \mathbf{P}\left(z_{0}, c, D\right)$ and having the form (4). Let also $0<\lambda<1$ and $f_{1}, f_{2} \in \mathbf{E P}\left(z_{0}, c, D\right)$ such that $f=\lambda f_{1}(1-\lambda) f_{2}$. Then

$$
\frac{\epsilon+z}{\epsilon-z}=\lambda^{*} g_{1}(z)+\left(1-\lambda^{*}\right) g_{2}(z) \text { in } U
$$

where

$$
\lambda^{*}=\lambda \frac{\operatorname{Re} f_{1}(0)}{\operatorname{Ref}(0)}, g_{i}(z)=\frac{f_{i}(z)-i \operatorname{Im} f_{i}(0)}{\operatorname{Re} f_{i}(0)}, i=1,2
$$

Since

$$
\frac{\epsilon+z}{\epsilon-z} \in \mathbf{E P} \text { and } g_{i} \in \mathbf{P}
$$

then

$$
\frac{\epsilon+z}{\epsilon-z}=g_{1}(z)=g_{2}(z) \text { in } U
$$

From the identity Theorem and the restrictions $f\left(z_{0}\right)=f_{1}\left(z_{0}\right)=f_{2}\left(z_{0}\right)=c$, we obtain $f=f_{2}$ and hence $f \in \operatorname{EP}\left(z_{0}, c, D\right)$.

\section{REFERENCES}

1. HOLLAND, F. The extreme points of a class of functions with positive real part. Math. Ann. 202, 85-87, (1973). 


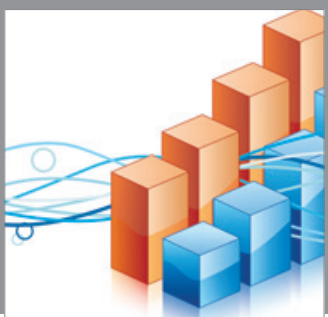

Advances in

Operations Research

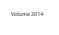

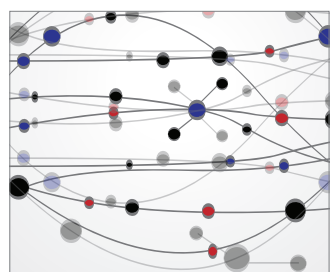

\section{The Scientific} World Journal
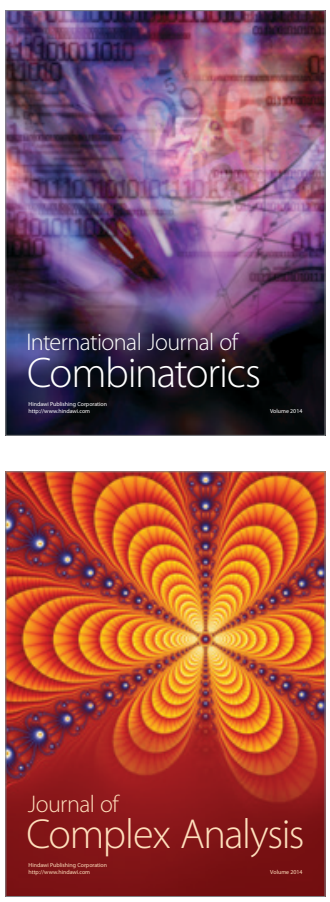

International Journal of

Mathematics and

Mathematical

Sciences
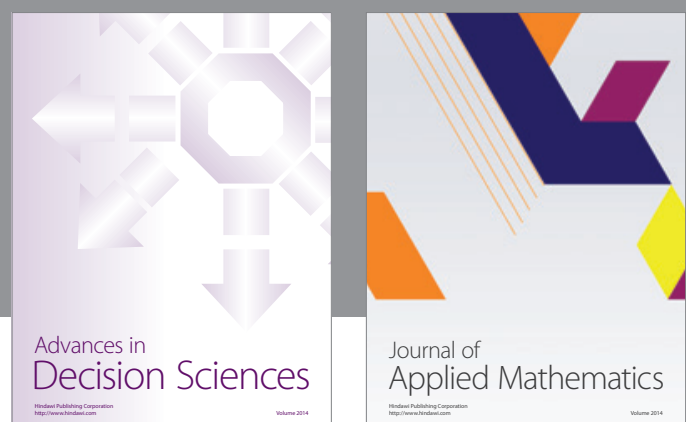

Journal of

Applied Mathematics
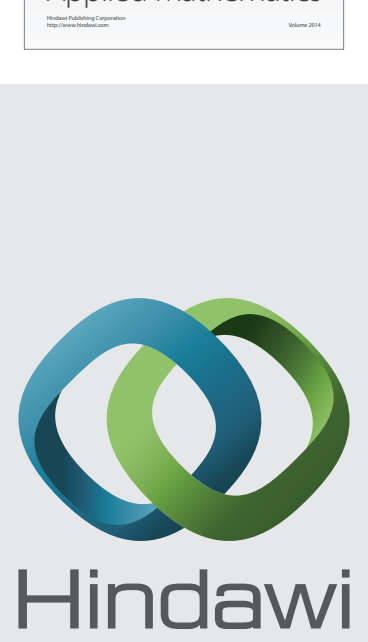

Submit your manuscripts at http://www.hindawi.com
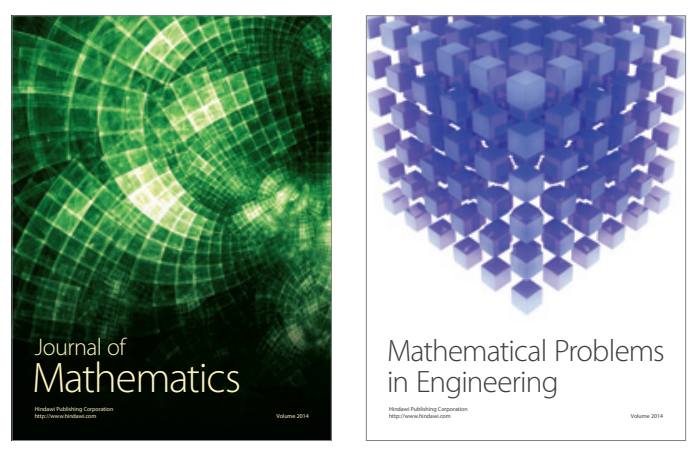

Mathematical Problems in Engineering
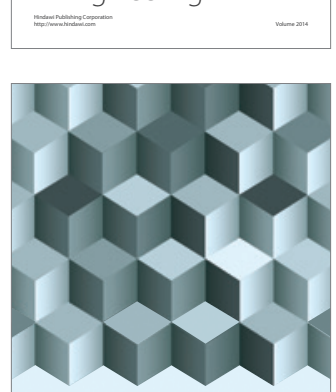

Journal of

Function Spaces
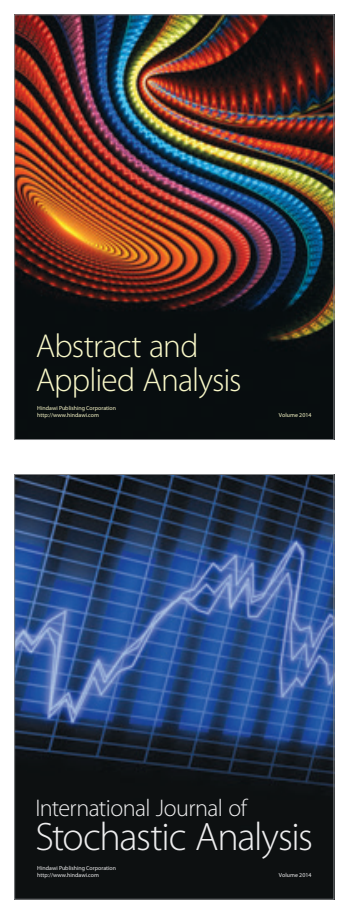

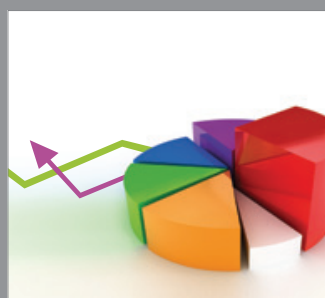

ournal of

Probability and Statistics

Promensencen
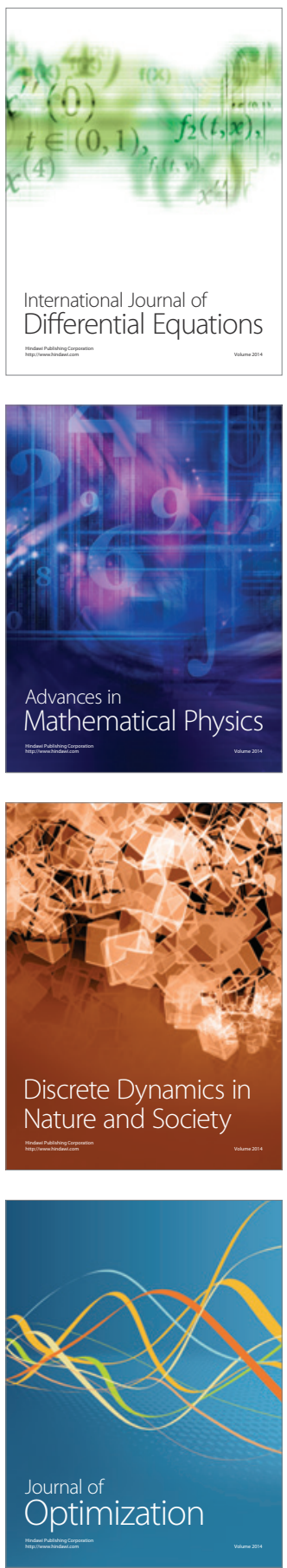